Egypt J. Aquat. Biol.\& Fish. Vol. lONo.l :211 - 215 (2006) ISSN 1110 - 6131

\title{
NEW KEY FOR ALGAL DIVISIONS
}

\section{A.S. Shaaban}

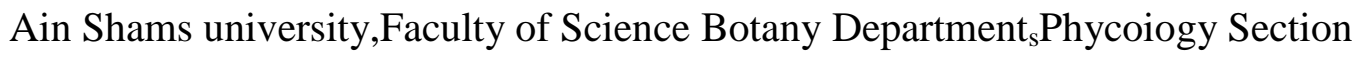
This is a key for identification of algal divisions by microscopic and macroscopic morphological characters of their members.

Key words: Algal divisions morphological characters.

\section{INTRODUCTION}

This key is intended to serve the purpose of students and workers in phycology and hydrobiology, who have often expressed their wish to an easy method to identify the qualitative and quantitative diversity of algal divisions present in each water sample with applied aspect of the percentage composition of algal populations and the number of individuals or taxa related to each division. Organisms to be placed among the algae is recognizethe following:

10divisioins:Cyanophycophyta,Rhodophycophyta,Euglenophycoph yta, Chlorophycophyta, Charophycophyta ,Bacillariophycophyta, Pyrrophycophyta ,Xanthophycophyta, Chrysophycophyta and Phaeophycophyta.

Keys specifically written on the identification of algal divisions are completely absent in the world literatures ( Rabenhorst, 1863 ;Pascher ,1907, 1913, 1915, 1925 and 1927 ;Prescott, 1931 ; Smith 1932 and Smith, 1950 and 1951). Key to the algal divisions

I. Algae large in size, reaching lengths of one meter or more, differentiated at apex, node and basal region, with whorls branches at nodes, on which apparently visible by simple eye multicellural reproductive organs. The basal potion in nature is typically attached to muddy or silty substrates by colorless rhizoids. Some are regularly confused with similar appearing aquatic flowering plants(Ceratophyllum spp.).Algae green in 